
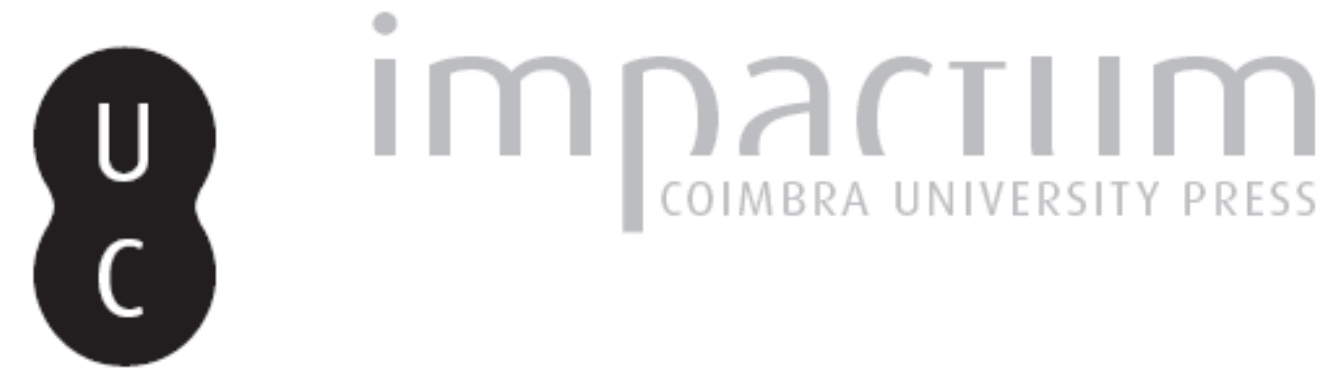

Entre a apologia e dissensão: a República Romana de 1849 na imprensa portuguesa Autor(es): $\quad$ Gomes, Marco

Publicado por: Imprensa da Universidade de Coimbra

URL persistente: URI:http://hdl.handle.net/10316.2/42552

DOI: $\quad$ DOI:https://doi.org/10.14195/0870-8584_6_9

Accessed : $\quad$ 26-Apr-2023 11:50:54

A navegação consulta e descarregamento dos títulos inseridos nas Bibliotecas Digitais UC Digitalis, UC Pombalina e UC Impactum, pressupõem a aceitação plena e sem reservas dos Termos e Condições de Uso destas Bibliotecas Digitais, disponíveis em https://digitalis.uc.pt/pt-pt/termos.

Conforme exposto nos referidos Termos e Condições de Uso, o descarregamento de títulos de acesso restrito requer uma licença válida de autorização devendo o utilizador aceder ao(s) documento(s) a partir de um endereço de IP da instituição detentora da supramencionada licença.

Ao utilizador é apenas permitido o descarregamento para uso pessoal, pelo que o emprego do(s) título(s) descarregado(s) para outro fim, designadamente comercial, carece de autorização do respetivo autor ou editor da obra.

Na medida em que todas as obras da UC Digitalis se encontram protegidas pelo Código do Direito de Autor e Direitos Conexos e demais legislação aplicável, toda a cópia, parcial ou total, deste documento, nos casos em que é legalmente admitida, deverá conter ou fazer-se acompanhar por este aviso.

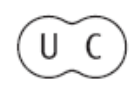




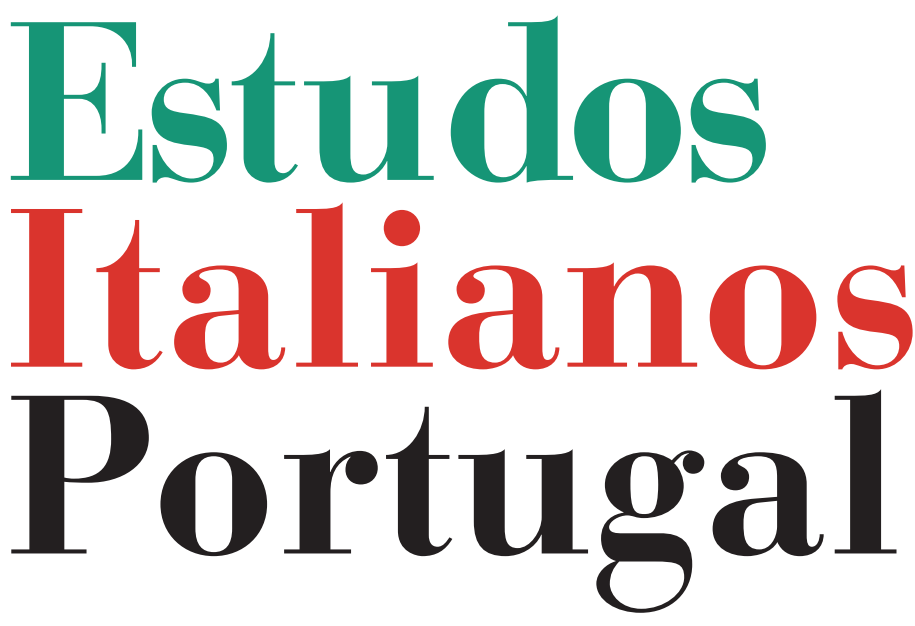

Instituto

Italiano

de Cultura

de Lisboa

Nova Série

$\mathrm{N}^{\circ} 6$ 


\section{ENTRE A APOLOGIA E DISSENSÃO. A REPÚBLICA ROMANA DE 1849 NA IMPRENSA PORTUGUESA}

Marco Gomes*

A Revolução Francesa inspirou, como é sabido, profundas rupturas no quadro político e social europeu, ao mesmo tempo que lançou as sementes das convulsões que haveriam de explodir em meados de Oitocentos. Este viés temporal, definido por Hobsbawm ${ }^{1}$ como "o mais revolucionário meio século da história até então registado", alterou a textura do conhecimento humano e colocou em marcha movimentos que lutaram contra as autocracias e a falta de representação política dos cidadãos. De carácter liberal, democrático e nacionalista, os processos revolucionários adquiriam amplitude em 1848 e clamaram, no contexto de crise económica, por uma nova ordem que diminuísse iniquidades.

A República Romana de 1849 enquadra-se neste contexto. Inspirada pelas novas ideias liberais, a experiência democrática durou cinco meses ( 9 de Fevereiro a 3 de Julho de 1849) e assinalou uma "fractura decisiva entre o Papa enquanto

*Marco Gomes (Santarém, 1978) é mestre em História das Ideologias e Utopias Contemporâneas, tendo publicado em 2009 o livro Comunicação política na revolução de Abril (1974-1976). Actualmente, é bolseiro da Fundação para a Ciência e Tecnologia e investigador do Centro de Estudos Interdisciplinares do Século XX), com um projecto de doutoramento sobre a análise, através da imprensa, do impacto do 25 de Abril em Itália.

${ }^{1}$ Eric Hobsbawm, A era das revoluções. 1789-1848, Lisboa, Presença, 1978, p. 403. 
Soberano temporal e os seus súbditos"2. Os Estados Pontifícios organizaram-se politicamente para viver sem o chefe do catolicismo ${ }^{3}$, adoptando princípios como a independência do poder espiritual e a liberdade de culto. Apesar de forte oposição, Roma foi derrotada pelo exército francês. Áustria, Espanha e o Reino das Duas Sicílias ${ }^{4}$ juntaram-se à iniciativa beligerante que visava restituir a autoridade papal. Mazzini foi a grande inspiração política da República e Garibaldi o símbolo da resistência.

As mutaçōes provocadas pelo meio século revolucionário incidiram igualmente sobre os domínios da ciência, da cultura e da comunicação. Portugal não passou à margem dessas tendências comutáveis. O surgimento do Estado Liberal, do espírito romântico e a necessidade de participar na vida pública - o designado espírito público - influíram sobremaneira na atmosfera comunicacional. $\mathrm{O}$ auditório português, ainda restrito, também testemunhou a eclosão da nova etapa na relação entre a mensagem do jornal e o destinatário. A imprensa tornou-se um meio de sociabilização, instrumento de combate político e de formação ideológica 5 .

O objectivo desta reflexão consiste em combinar estas duas dimensões da novidade oitocentista, confrontando espaços

2 Federico Curato, "Il 1848 italiano ed europeo", in Nuove questioni di storia del Risorgimento e dell'unità d'Italia, Milano, Marzorati, 1961, pp. 691-692. Cf. Dizionario del Risorgimento nazionale. Dalle origini a Roma capitale. Fatti e Persone, Milano, Vallardi, vol. I, 1931, pp. 891-915.

${ }^{3}$ Pio IX fugiu para Gaeta em novembro de 1848. A República formou uma Assembleia Constituinte com base no contributo popular e aprovou várias medidas anticlericais. A Constituição romana figurava entre as mais avançadas da Europa, promovendo um estado laico, conferindo liberdade de culto e abolindo a pena de morte. Cf. Domenico Demarco, Una rivoluzione sociale. La Repubblica romana del 1849 (16 novembre 1848-3 luglio 1849), Napoli, Edizioni Scientifiche Italiane, 1992.

${ }^{4}$ A intervenção limitou-se aos Estados Pontifícios. Apenas os franceses combateram Roma.

${ }^{5}$ Sobre a importância da imprensa na formação da ideologia, ver Antonio Gramsci, Quaderni del carcere, Torino, Einaudi, 1975, pp. 2257-2276. 
distintos mas temporalmente contemporâneos. Pretendemos, pois, analisar as repercussões da República Romana na imprensa portuguesa, procurando, sobretudo através dos editoriais, deconstruir a moldura interpretativa (frame) veiculada por dois dos mais proeminentes órgãos do panorama jornalístico português do século XIX, A Revolução de Setembro e A Nação ${ }^{6}$. Ou seja, discorrer acerca do elemento que confere sentido, segundo Goffman, às situaçōes construídas de acordo com os princípios de organização que governam os eventos, pelo menos os sociais, e o nosso envolvimento subjectivo neles ${ }^{7}$, não deixando de estabelecer os vínculos entre as instâncias enunciadoras e as correntes de opinião que lhes estão associadas.

\section{A IDEOLOGIA AO SERVIÇO DA OPINIÃO PÚBLICA}

Qual a pertinência dos eventos italianos para a opinião pública portuguesa? Trata-se de um acontecimento que envolveu directamente a autoridade máxima do mundo católico. Esse motivo bastava para que $A$ Nação, defensor da Igreja Católica, redobrasse a sua atenção: "A questão romana não tem para nós o mesmo interesse que outra qualquer. Roma significa muito mais que Paris, Madrid ou Viena. [...] Roma é a sede da suprema direcção do Papado, e esta questão interessa a todo o orbe católico" ${ }^{8}$. A interpretação dos factos longínquos revelou-se importante para cimentar a posição ideológica do periódico no plano interno, vinculando os interesses dos portugueses às ocorrências da península itálica: "Aqueles estados não pertencem ao Papa, são da cristandade. Ali não residem os interesses de um só povo, [...] contêm os interesses do mundo cristão"'.

${ }^{6}$ A Revolução de Setembro (1840-1892) e A Nação (1847-1889) foram os jornais portugueses com maior longevidade no século XIX.

${ }^{7}$ Erving Goffman, Frame Analysis. An Essay on the Organization of Experience, Boston, Northeastern University Press, 1986, pp. 10-11.

${ }^{8} A$ Nação, n. ${ }^{\circ}$ 544, 20-7-1849, capa,

${ }^{9}$ A Nação, n. ${ }^{\circ}$ 613, 10-10-1849), capa. 
A insurreição romana anunciou ainda a vitalidade e afirmação das forças revolucionárias. Significou a vitória da liberdade e dos princípios democráticos que também enformaram, em Portugal, a Revolução de 1836, acontecimento que inspirou A Revolução de Setembro e ao qual foi buscar o nome. A constituição da República Romana conferiu ao periódico de António Rodrigues Sampaio ${ }^{10}$ mais um argumento para a defesa das liberdades democráticas, das ideias humanitárias e da legitimidade revolucionária. Possibilitou a identificação de Portugal e Roma com os povos pequenos, unidos no combate contra os opressores e os inimigos estrangeiros.

Apresentando um posicionamento ideológico oposto, os dois órgãos de Lisboa vestiram a indumentária do testemunho político-partidário, $A$ Nação de tendência legitimista e A Revolução de Setembro associado à linha da esquerda liberal triunfante em $1836^{11}$. Aliás, foi a partir da insurreição de 9 de Setembro que se assiste, mais consistentemente, ao alargamento da participação política das populações, ao maior interesse pelas questões do regime político, à existência de uma comunicação mais regular e diversificada que, extravasando as fronteiras da formalidade, coloca-se ao serviço da disseminação de ideias ${ }^{12}$. Foram os jornais, como refere José Tengarrinha $^{13}$, que por esta altura mais contribuíram para cumprir esta missão, enquanto "um dos principais factores de abertura e dinamização do espaço público politizado" e elemento nuclear de organização da vida política, de supressão das carências afectas aos grupos políticos.

${ }^{10}$ António Rodrigues Sampaio assumiu a direcção do jornal em 1844.

${ }^{11}$ Depois da Regeneração (1851), o jornal inflectiu para posições mais moderadas de orientação progressista regeneradora. Ver José Miguel Sardica, "A vida partidária portuguesa nos primeiros anos da Regeneração", Análise Social, 32 [1. ${ }^{\circ}$ ], n. ${ }^{\circ}$ 140, 1997 [Lisboa, Instituto de Ciências Sociais da Universidade de Lisboa], pp. 747-777.

${ }^{12}$ José Tengarrinha, Imprensa e opinião pública em Portugal, Coimbra, Minerva, 2006, passim.

${ }^{13}$ Ib., pp. 157- 158 . 
O papel sempre mais activo ao nível da promoção e organização das correntes de opinião, com os limites que esta eficácia comporta em meados de Oitocentos, permitiu à imprensa influenciar a agenda política dos governos e a temperatura da opinião pública. No entanto, seguindo as concepções de Almeida Garrett ${ }^{14}$, este esforço deveria privilegiar a formação e orientação de opiniões esclarecidas enquanto pilar basilar da sociedade liberal. Devido às suas características, os jornais estavam em melhor posição para desempenhar essa função. Cidadãos elucidados conferiam mais solidez ao sistema político. Garrett rejeitava ser levado pela "estupidez da massa ignorante, tão inábil para conceituar de um princípio, como para lhe calcular ou observar as consequências". Era na "porção ilustrada da população" que residia a legítima consciência da pátria, fundamental para o sistema de governo e administração ${ }^{15}$. A noção de classe média afigura-se indispensável para compreender o pensamento garrettiano.

O jornalismo português do século XIX actuou, como é óbvio, em conformidade com o indissociável axioma da história da imprensa, desde sempre dialecticamente interligada com as variegadas formas de governação e acção política. A Revolução Francesa e as suas duradouras réplicas conferiram substância a esta regra de ouro do periodismo. E não é por acaso que a República Romana se preocupou rapidamente

${ }^{14}$ Almeida Garrett, Carta de guia para eleitores, Lisboa, Veja, 2005, pp. 26-27. Cf. José Augusto dos Santos Alves, "Almeida Garrett e a opinião pública em Portugal na terceira década do século XIX", Cultura. Revista de História e Teoria das Ideias, 14, 2002 [Lisboa: Universidade Nova de Lisboa], pp. 203-217.

${ }^{15}$ Como nota José Tengarrinha, importa enquadrar estas noções no tempo. Diferente do sentido actual, o vocábulo democracia era entendido, na altura, como a voz anárquica da multidão. Muitos correligionários de Garrett rejeitavam esta democracia, o que não quer dizer que não se empenhassem na democratização do regime liberal, tal como hoje entendemos a democracia (Imprensa e opiniāo). Garrett insistiu na promoção da consciência política dos cidadãos. Só assim era possível, segundo ele, criar uma opinião pública habilitada a interpretar as ideias veiculadas pelos grupos geradores de crença política. Os jornais constituíam a correia transmissora desses círculos políticos. 
em publicar o seu jornal oficial, o Monitore Romano, cujo número inaugural saiu a 30 de Janeiro. Concluído o ensaio democrático, os franceses logo trataram de substituí-lo pelo Giornale di Roma, estando o primeiro número datado de 6 de Julho, três dias após a queda da República.

INFORMAR, ESCLARECER E CATIVAR. PERCEPÇÕES DISTINTAS DO MESMO ACONTECIMENTO

A partir da frequência e extensão dos editorais, das notícias - comentadas - elaboradas com base em informação de jornais estrangeiros e da correspondência proveniente da península itálica, podemos concluir ter sido bastante relevante o impacto dos eventos italianos na agenda de $A$ Nação e $A$ Revolução de Setembro. Os jornais convergiram, desde meados de Abril, na crítica - muito enfatizada - à intervenção militar francesa, salientado o carácter ambíguo e contraditório das disposições de Luís Napoleão em relação ao futuro de Roma e ao restabelecimento da autoridade papal. $\mathrm{O}$ cenário de guerra que devastava, progressivamente, a Europa foi encarado como periclitante ameaça à estabilidade política e surgiu como referência transversal aos editoriais analisados.

Individualizando as repercussões do conflito romano, é possível identificar vários planos de tendência na argumentação de cada um dos órgãos de comunicação. A Revolução de Setembro insistiu, naturalmente, em defender a legitimidade da República e a acção dos revolucionários. "Em Roma não há só um papa de menos, há também uma república de mais, e um governo que a quer sustentar. Por isso os bens que usufruía a Igreja revertem ao estado a quem de direito pertencem [...]", assim começou o editorial de 20 de Março, ocupando duas colunas e meia das três disponíveis, na capa. $\mathrm{O}$ texto deu origem a uma intensa querela com $A$ Nação em redor da questão da propriedade dos bens eclesiásticos, da administração do território e das liberdades públicas. Argumentava A Revolução que o governo dos Estados Pontifícios havia sido 
"miserável”. Os cardiais usavam "indecorosamente" as suas riquezas, os campos mantinham-se incultos, as cidades repletas de vadios, o catolicismo alimentava-se do esplendor das suas festas, o ruinoso estado das finanças apenas encontrava em Portugal um semelhante. Tudo isto havia apressado a revolta contra - como sustentava - a omnipresença de um catolicismo que não precisava da servidão de nenhum povo ${ }^{16}$.

Mesmo na hora da capitulação, não se coibiu de sublinhar a vitória moral de Roma: "A república romana é já uma epopeia. [...] A sua guarda é o anjo da democracia"17. Criticou a intervenção estrangeira na península e os intentos destabilizadores que a norteavam. Não restavam dúvidas quanto à finalidade do jugo inimigo: impedir a independência de Itália.

Sem deixar de reprovar a actuação de Pio IX e do clero romano em relação à utilização da religião enquanto instrumento político, revelou-se bastante cáustico quando comentou a situação político-social francesa e a política externa. O país vivia mergulhado em convulsóes sociais e as pretensões monárquicas eram incompatíveis com a II República. Em relação a Roma, "A irmã matara a irmã. A mãe matara a filha" ${ }^{18}$. A acção beligerante, sublinhava $A$ Revolução, havia provocado manifestaçóes populares em Paris, inflamados debates no âmbito da política interna francesa e colocado os poderes públicos em conflito.

Acusou o executivo de Napoleão III de nunca esclarecer qual o verdadeiro objectivo da acção militar na capital dos Estados Pontífices. Um sinal da contradição da sua política que ficou bem patente quando a Assembleia Nacional francesa lançou um voto de censura ao governo, depois de tomar conhecimento do desaire do exército liderado pelo general

\footnotetext{
${ }^{16}$ A Revolução de Setembro, n. ${ }^{\circ} 2104,20-3-1849$, capa.

${ }^{17}$ A Revolução de Setembro, n. ${ }^{\circ} 2160,29-5-1849$, capa.

${ }^{18}$ A Revolução de Setembro, n. ${ }^{\circ} 2135,28-4-1849$, capa.
} 
Oudinot às portas de Roma, durante a primeira ofensiva. Segundo o periódico, a iniciativa francesa estava envolta em neblina porque a sua finalidade primeva remetia para a salvaguarda das liberdades constitucionais em Itália, "a liberdade do povo romano, nenhuma influência na sua forma de governo. [...] A aproximação do exército era sempre para libertar o povo romano" 19 . Em Roma permanecia o sentimento de que a expedição respondia a uma missão de observação contra os austríacos. Por outro lado, os franceses haviam declarado explicitamente que não iam restaurar o papa $^{20}$.

$\mathrm{O}$ resultado final foi, porém, totalmente contrário ao princípio que ditara a intervenção. Escrevia A Revolução: "O general Oudinot aclamara o papa contra o que tinha proclamado, e restabeleceu as jurisdiçóes eclesiásticas contra o que tinham prometido na câmara os ministros da república"21. Interpretando alguns despachos de Nicolas Oudinot, não hesitou em afirmar que as tropas francesas pelejavam o governo romano pelo mesmo princípio que combatiam os socialistas em Paris. O triunvirato de Mazzini - referia o general era obra do partido vermelho. E, sendo inimigo do vermelho em França, o governo de Luís Napoleão só poderia declarar guerra à mesma cor em toda a parte ${ }^{22}$.

O jornal concluía que a França, movida por interesses políticos, se deslocara a Itália para impedir que a Áustria resolvesse a questão sozinha. $\mathrm{O}$ espírito democrático estava destruído. Principalmente porque a Assembleia Nacional, apesar de reconhecer que a matriz inicial da expedição havia sido desvirtuada e as resoluçóes falsificadas, transmitira a confiança ao governo de Napoleão, permitindo que este saísse do imbróglio criado de cabeça erguida.

\footnotetext{
${ }^{19}$ A Revolução de Setembro, n. ${ }^{\circ} 2227,21-8-1849$, capa.

${ }^{20} \mathrm{Ib}$.

${ }^{21} \mathrm{Ib}$.

${ }^{22}$ A Revolução de Setembro, n. ${ }^{\circ}$ 2157, 25-5-1849, pp. 2-3.
} 
O papa regressou à città eterna apenas quando recebeu garantias de não interferência nos assuntos da Igreja. Até Abril de 1850, julgou insuficientes as condições para exercer as suas funçôes. Roma estava ocupada pelo exército francês. A moldura constitucional de restauração da jurisdição eclesiástica constituíu o último capítulo através do qual a imprensa se esforçou para esclarecer a opiniāo pública portuguesa. Pio IX prometeu reformas, por motu proprio, em conformidade com as disposições emanadas pelo governo francês - amnistia geral, secularização da administração, legislação francesa (Código Napoleónico) e um governo de tendência liberal. Não esquecendo a permanência da supressão da liberdade de imprensa e as deportaçôes ("a Roma francesa é mais escrava que a Roma dos padres”), A Revolução de Setembro logo levantou a voz contra as deliberaçōes estrangeiras, corroborando as resistências do papa: "Se restabeleceram o seu poder temporal, é um absurdo querer torna-lo dependente. Se tem poder, deixem-no ser livre. Se querem pôr condições, ajustassem-nas primeiro"23. E quando escalpelizou o teor das exigências não teve dúvidas em afirmar que se tratava do restabelecimento da República Roma. A pergunta era inevitável: "Para que derrubaste Mazzini?"24.

Sobre a questão que encerrou uma história destinada a perpetuar a influência francesa no coração da península italiana, $A$ Nação não olhou aos seus valores católicos e desaprovou a atitude do papa em ceder às pretensôes de Luís Napoleão: "Os anti-revolucionários não podem fiar-se num governo que ataca a independência dos governos legítimos da Itália e que quer ditar condições como se fosse o dono da Itália" ${ }^{25}$. Afirmou que o Sumo Pontífice caíra no erro de, por um lado, ceder às exigências e, por outro, desejar resistir às

\footnotetext{
${ }^{23}$ A Revolução de Setembro, n. ${ }^{\circ} 2227,21-8-1849$, capa.

${ }^{24}$ A Revolução de Setembro, n. ${ }^{\circ} 2253$, 20-9-1849, capa.

${ }^{25}$ A Nação, n. ${ }^{\circ}$ 597, 21-9-1849, capa.
} 
mesmas. Relembrou que, antes de despoletar a insurreição romana, já tinha levantado sérias dúvidas quanto aos intentos liberalizantes de Pio IX. O resultado - salientava - veio pouco tempo depois com a demagogia e a intolerância revolucionária. Diante da hesitação de papa, A Nação apontou novo erro político com base na concessão ao espírito reaccionário francês ${ }^{26}$.

Efectivamente, poucas nuances em todo este processo foram do agrado do periódico. E por isso bateu-se pelos seus ideais na convicção de representar a corrente de opiniōes católica e legitimista. Como já referimos, a expedição francesa foi consistentemente censurada desde o início. O conteúdo dos fundamentos preconizados - ambiguidade, duplicidade política - não diferiu muito do discorrimento apresentado por A Revolução de Setembro. A reprovação avolumou-se quando o general tornado chefe anunciou a liberdade aos romanos, ocultando o nome do papa. Pouco depois, os republicanos, forasteiros, pregadores da liberdade tomavam Roma e destruíam a República. A Nação escreveu que era impossível estabelecer harmonia entre os mandatários franceses e o governo pontífice ${ }^{27}$. Havia sempre defendido que a Áustria detinha mais legitimidade para realizar a acção militar em Roma. Até porque era fundamental um império austríaco forte para contrabalançar a influência francesa na península itálica.

O desagrado pelas posições de Pio IX em relação às ordenações de Paris não minimizou, porém, o empenho de $A$ Nação na defesa e apologia do catolicismo e da autoridade papal. Reclamando maior atenção para os assuntos do clero português, reiterou os vínculos que uniam Portugal ao mundo cristão e atacou a leviandade (principalmente de $A$ Revolução de Setembro) com que eram tratados os assuntos da Igreja:

\footnotetext{
${ }^{26}$ A Nação, n. ${ }^{\circ}$ 613, 10-10-1849, capa.

${ }^{27}$ A Nação, n. ${ }^{\circ}$ 597, 21-9-1849, capa.
} 
"Que significa um Papa de menos em Roma? É isto que $A$ Revolução deveria ter pensado antes de escrever aquelas palavras, que são um verdadeiro escândalo" 28 . Elogiou também a recusa dos sacerdotes em votar na Assembleia Constituinte da República, definindo o gesto como um acto de coragem.

O tom mais efusivo, irónico e corrosivo dos enunciados esteve sempre presente quando a questão romana foi abordada. Três propósitos nortearam o esforço narrativo de $A$ Nação: desqualificar a República e os protagonistas, vincular os seus leitores à luta anti-revolucionária que devastava os governos legítimos e a Europa; e combater os pontos de vista de outros órgãos de comunicação que disseminavam concepçôes ideológicas dissonantes. Sobre a experiência democrática impulsionada por Giuseppe Mazzini e seus correligionários, recaíram aviltadas considerações: bando de facciosos despóticos, manipuladores da soberania popular; punhado de impios, cruéis e ferozes demagogos de barrete vermelho cuja finalidade, assente em desmesurada ambição, se centrava no engrandecimento pessoal - "Subir é o grande princípio, não descer a primeira das necessidades. [...] A opinião pública sabem eles traduzir sempre de modo de que nunca seja prejudicial ao seu interesse pessoal" 29 .

Era, pois, uma República preocupada em perpetuar publica e impunemente todos os delitos, dos incêndios e roubos aos assassínios de sacerdotes e insultos aos bispos, da usurpação à corrupção e violência de correspondência particular. $\mathrm{O}$ jornal lembrou que os revolucionários saudavam a liberdade de imprensa e de pensamento ao mesmo tempo que não davam notícia de todas as atrocidades que iam realizando. $\mathrm{O}$ ataque aos bens eclesiásticos figurou no topo das preocupaçôes de $A$ Nação, notando que a propriedade era, para os romanos, sinónimo de espoliação e a delapidação o meio

\footnotetext{
${ }^{28} A$ Nação, n. ${ }^{\circ} 388$, 5-1-1849, capa-p.2.

${ }^{29}$ A Nação, n.o 406, 29-1-1849, capa.
} 
governativo. O editorial de 16 de Março, a três colunas, comentou eloquentemente o decreto romano do Ministério da Fazenda: "Parece que as irrisoriamente denominadas ideias de progresso não podem coexistir com as ideias religiosas. [...] Quer sejam liberais os seus apóstolos, ou se apelidem de republicanos, tudo o que cheira a Igreja atrai a sua raiva ou a sua fome" 30 .

Advogou que, em virtude das loucuras e dos crimes revolucionários, o problema romano tornava-se impossível de resolver sem o recurso às armas. Outra significativa formulação prendeu-se com a necessidade de traçar o quadro evolutivo das forças revolucionárias e os perigos que estas representavam. Dizia o periódico que a Europa atravessava uma fase gravíssima, sendo necessário opor a solidariedade salvadora à solidariedade revolucionária. Chamou a atenção dos estadistas para que não pensassem que existiam revoluçôes que não o eram, ou ilegitimidades que serviam de apoio a legitimidades. E constatou que os governos legítimos haviam, por vezes, caído no erro de atribuir aos povos um carácter revolucionário. Ideia logo desmistificada: "Nenhum povo é revolucionário porque nenhum homem é suicida" ${ }^{31}$. A avaliação global impunha, segundo $A$ Nação, a deconstrução das diversas máscaras com que a revolução, não raras vezes, se apresentava: religiosa, nacionalista, reaccionária, republicana ou monárquica. Porém, no final, destacou que se tratava de um período transitório, efémero, e que era "necessário descer à arena e aceitar o duelo" 32 .

\section{A (IN)COMUNICABILIDADE DA ORATÓRIA ESCRITA}

Ainda longe dos postulados deontológicos associados à imprensa independente ou de informação, $A$ Nação e $A$

\footnotetext{
${ }^{30}$ A Nação, n. ${ }^{\circ} 444,16-3-1849$, capa.

${ }^{31}$ A Nação, n. ${ }^{\circ}$ 536, 11-7-1849, capa-p. 2.

${ }^{32}$ A Nação, n.o 573, 24-8-1849, capa.
} 
Revolução de Setembro cumpriram a tarefa de transmitir a mensagem dos grupos políticos que lhes serviam de referência. Os editoriais analisados privilegiaram a eficácia da acção política, o exercício da autoridade institucional, legitimando estratégias e orientando a formação da opinião. Os espaços dedicados às notícias discorreram sobre eventos e actores sem a obrigatoriedade de os estruturar num todo coerente. Em consonância com as noçôes de Almeida Garrett, os jornais procuraram publicitar uma determinada percepção do mundo social. E empregaram uma linguagem caracterizada pela prosa oratória, irónica, violenta, metafórica, triunfalista, de tom panfletário e impregnada de chavões doutrinários. Este era o quadro normativo que regia a actividade da imprensa e do jornalismo. Deve, por isso, ser interpretado à luz do seu tempo e não como um esforço para restringir as subjectividades expressas.

A adesão do auditório aos fundamentos invocados constitui a finalidade nuclear do exercício persuasivo. A comunicação argumentativa visa, por um lado, conservar e conquistar o assentimento intelectual e, por outro, instigar à acção. $\mathrm{Ou}$, em última análise, criar uma tendência para a acção ${ }^{33}$. Os periódicos seguiram a dimensão ilocutória dos actos de fala $^{34}$, expondo valores, anunciando soluções e determinando arquétipos de interpretação que enformam a realidade apreendida. Mas todo o processo de persuasão implica partilha e reconhecimento dos códigos dos enunciados. Coloca-se então a questão, em meados de Oitocentos, da penetração da mensagem, frequentemente hermética devido à, ainda, limitada politização do espaço público e exiguidade do auditório. Mesmo apesar dos notáveis progressos e transformações que se verificaram a partir, principalmente, da terceira década do

${ }_{33}$ Chaïm Parelmen, O império retórico. Retórica e argumentação, Lisboa, ASA, 1999 , p. 31.

${ }^{34}$ John Austin, How to do Things with Words, London, Oxford University, 1978, p. 99. 
século XIX, passando os jornais a representar "o centro da vida política e social", em redor dos quais se agrupavam os leitores de acordo com as preferências ideológicas ${ }^{35}$. Realidade, no entanto, mais visível nos centros urbanos. O que nos leva a concluir que a oratória escrita evoluiu numa espécie de areópago restrito e que o debate em torno da República Romana, não obstante o empenho de $A$ Nação e de A Revolução de Setembro, se circunscreveu, de certa forma, à assembleia dos próceres ou aos cidadãos mais aptos para interpretar e redimensionar as mensagens.

${ }^{35}$ José Tengarrinha, História da imprensa periódica portuguesa, Lisboa, Caminho, 1989 , p. 205. 